\title{
Research and Analysis of Axial Compressive Properties of Concrete Columns Strengthened with Composited Fiber Cloth
}

\author{
Zhu Kun, Pang Boshi, Luo Hangyu, Zhang Wenjia, Chen Ran, Wang Kai \\ Changchun Institute of Technology, The Key Laboratory of Earthquake Disaster Reduction for Civil Engineering in Jilin Province China, \\ Changchun 130012
}

\begin{abstract}
Paste fiber cloth reinforcement method is an important method in the current reinforcement project, and carbon fiber reinforced plastics (CFRP) and glass fiber reinforced plastics (GFRP) are the two most commonly used materials in the reinforcement method. CFRP have high tensile strength, high elastic modulus, and low elongation, while GFRP have lower tensile strength and elastic modulus, but high elongation. Studies have shown that the combination of two fiber materials can effectively improve the weakness of a single fiber material, make better use of the advantages of these two materials, and improve the comprehensive mechanical properties of the fiber material. Columns, as the main load-bearing components in the concrete structure system, have a significant impact on the stability of the building structure. By studying the influence of the combined fiber cloth on the compressive performance of the column, the optimal fiber cloth combination scheme was found out, which provides a reference for practical engineering applications.
\end{abstract}

\section{Introduction}

Since 1997, China began to introduce fiber plastics to strengthen concrete structure technology from abroad. The fiber cloth reinforcement technology has the advantages of convenient construction, can cover various complex shapes of structural cross-sections, and does not increase its own weight, which makes this technology become a hotspot for research and engineering application [1].

Relevant experts and scholars have studied the reinforcement of reinforced concrete structures with FRP. Gu Qian and others tried a new method of spraying CFRP to strengthen concrete columns and applied low-cycle repeated loads to these columns. It was found that its design bearing capacity, and its ductility and energy consumption are better than before reinforcement, which proves that this new reinforcement method is effective [2]. $\mathrm{Su}$ Zhi et al. carried out an axial compression test on a steel double-pipe long column made of GFRP reinforced recycled concrete, taking the loading method and the slenderness ratio as variables, analyzed the effects of these two variables on the axial compression bearing capacity and ductility of the test column, and the correlation curve was drawn [3]. Based on the seismic performance test results of reinforced corroded concrete columns reinforced with hybrid FRP, Deng Zongcai et al. established the restoring force model and skeleton curve of the test piece, which are in good agreement with the actual test results [4].

Relevant experts and scholars carry out experimental and theoretical research on reinforced concrete structures strengthened with fiber cloth of various materials. Chu Yunpeng et al. conducted an experimental comparison of two interlayer hybrid fiber reinforced concrete-damaged reinforced concrete beams with one unreinforced beam and two single fiber reinforced beams, and found that: hybrid fiber reinforcement can significantly increase the bearing capacity of the beam; and compared with the test beam strengthened with a single CFRP cloth, the test beam strengthened with hybrid fiber shows better ductility, and its initial stiffness is higher than that of the unreinforced beam [5]. Xiong Guangjing et al. conducted a comparative test of interlayer mixed fiber reinforced concrete columns and single fiber reinforced or unreinforced concrete columns (plain concrete columns). The efficiency of a single fiber reinforcement is low; when the interlayer hybrid fiber cloth is used for reinforcement, the strain of the hybrid fiber cloth is increased by 3 to 5 times, which significantly improves the ductility and bearing capacity of the test column, and the construction cost is lower [6 ]. Christopher Quon et al. studied the basic mechanical properties of the bistable system formed by the "connection" of carbon fiber and glass fiber, so as to avoid the situation that the ductility of FRP confined concrete is limited by the low fracture strain and brittleness of fiber material and the energy consumption is low. It was found that concrete has good ductility and energy absorption performance under the FRP bistable constraints. A two-step numerical simulation method for FRP cloth confined concrete is established and a simplified bilinear model is proposed [7]. 


\section{Test design}

\subsection{Test block design}

In order to study the effect of the combined action of CFRP cloth and GFRP cloth on the axial compressive bearing capacity of concrete square columns, this test was planned as 5 groups of test pieces. Z1 was a concrete column reinforced with non-fiber cloth as the reference column for this test; Z2 was a concrete column reinforced with glass fiber cloth, using Class E glass fiber cloth with a width of $100 \mathrm{~mm}$; Z3 was a reinforced concrete square column wrapped in carbon fiber sheet, using $100 \mathrm{~mm}$ width Class I carbon fiber cloth; Z4 was the concrete square pillars reinforced by interlayer combination of glass fiber cloth and carbon fiber cloth, that is, the first layer was fully wrapped with $100 \mathrm{~mm}$ width Class I carbon fiber cloth, and the second layer was fully wrapped with Class E glass fiber cloth with a width of $100 \mathrm{~mm}$. This combination of fiber cloth is referred to as JFRP hereinafter; Z5 was a concrete square column that combines two kinds of fiber cloth in the same layer and completely wraps two layers of reinforced concrete, that is, carbon fiber cloth and glass fiber cloth were arranged at the same layer. From top to bottom, firstly wrap two layers of carbon fiber cloth of Class I with a width of $100 \mathrm{~mm}$, and then wrap two layers of fiberglass cloth of Class E with a width of $100 \mathrm{~mm}$, until the concrete square column is fully wrapped and strengthened. Hereinafter, the fiber cloth combined in this way is simply referred to as NFRP. The detailed reinforcement scheme of the test piece is shown in Table 1, and the fiber cloth reinforcement design is shown in Figure 1.

The reinforced concrete column was made of concrete with strength class $\mathrm{C} 25$, and the compressive strength design value was $f_{c}=11.9 \mathrm{~N} / \mathrm{mm}^{2}$. The cross-sectional size of the reinforced concrete column was $250 \mathrm{~mm} \times 250 \mathrm{~mm}$, the height was $1000 \mathrm{~mm}$, and the thickness of the protective layer was $30 \mathrm{~mm}$. The longitudinal steel bar was selected as HRB335, the diameter was $d=12 \mathrm{~mm}$, the design value of tensile strength was $f_{y}=300 \mathrm{~N} / \mathrm{mm}^{2}$, the design value of compressive strength was $f_{y}=300 \mathrm{~N} / \mathrm{mm}^{2}$, the model of steel bar was HPB300, and the standard value of yield strength was $f_{y k}=300 \mathrm{~N} / \mathrm{mm}^{2}$. The stirrup diameter was chosen to be $8 \mathrm{~mm}$, the stirrup spacing in the encrypted area of the component stirrup was $100 \mathrm{~mm}$, the stirrup spacing in the non-encrypted area was $150 \mathrm{~mm}$, and the range of the reinforced area was to extend $250 \mathrm{~mm}$ into the column. $250 \mathrm{~mm} \times 250 \mathrm{~mm} \times 10 \mathrm{~mm}$ thick steel plates were set at both ends of the column to achieve uniform stress on the end of the column and prevent end damage. The test piece size and reinforcement arrangement are shown in Figure 2.
Table 1. Reinforcement scheme of test piece

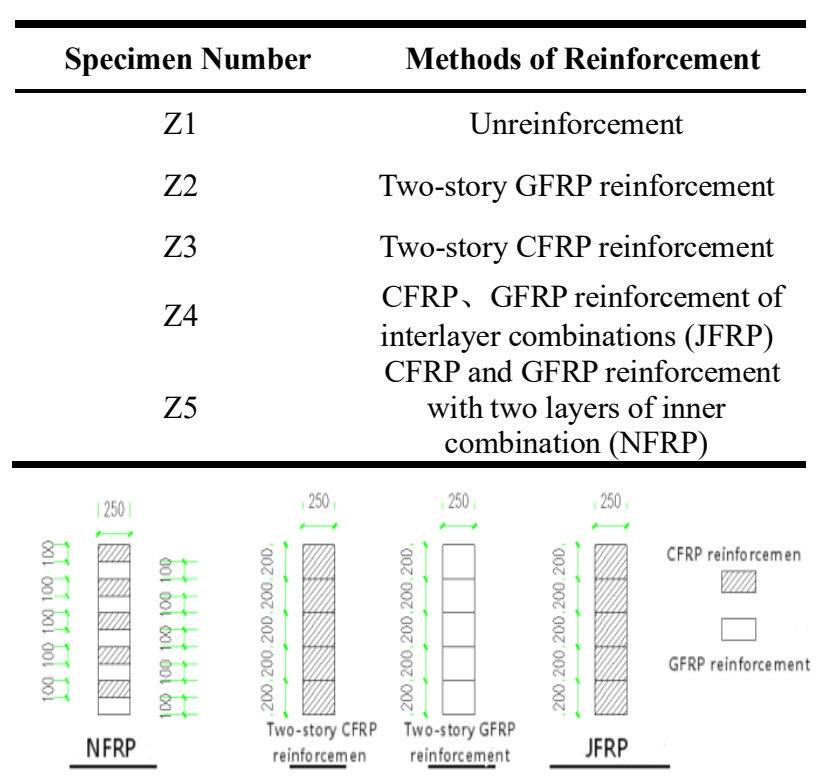

Fig. 1. Design drawing of fiber cloth reinforcement

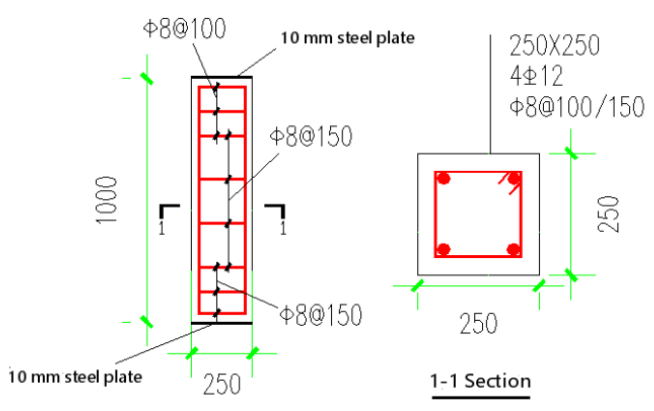

Fig. 2. Dimensions and reinforcement arrangements

\subsection{Mechanical properties of materials}

According to the specification [8], after the produced test specimens are cured for 28 days, the relevant cubic compressive strength, axial compressive strength and concrete elastic modulus are tested strictly in accordance with the requirements. See Table 2 for specific performance indicators. The basic mechanical properties of the longitudinally-stressed main tendons were tested according to the code [9]. The specific performance indicators are shown in Table 3.

The fiber cloth was divided into four groups: two layers of CFRP, two layers of GFRP, two layers of JFRP, and two layers of NFRP. The mechanical properties was in accordance with the specification [10]. See Table 4 for specific performance indicators.

Table 2. Basic mechanical properties of concrete

\begin{tabular}{ccccc}
\hline Concrete type & Strength grade & $\begin{array}{c}\text { Cube compressive } \\
\text { strength } \\
(\mathrm{MPa})\end{array}$ & $\begin{array}{c}\text { Axial compressive } \\
\text { strength } \\
(\mathrm{MPa})\end{array}$ & $\begin{array}{c}\text { Compressive } \\
\text { elastic modulus } \\
(\mathrm{GPa})\end{array}$ \\
\hline $\mathrm{PI} 42.5$ & $\mathrm{C} 25$ & 28.4 & 18.2 & 18.6 \\
\hline
\end{tabular}


Table 3. Basic mechanical properties of longitudinal bars under stress

\begin{tabular}{ccccccccc}
\hline Grade & Form & $\begin{array}{c}\text { Diameter } \\
(\mathrm{mm})\end{array}$ & $\begin{array}{c}\text { Gauge } \\
\text { length } \\
(\mathrm{mm})\end{array}$ & $\begin{array}{c}\text { Yield } \\
\text { strength } \\
(\mathrm{MPa})\end{array}$ & $\begin{array}{c}\text { Ultimate } \\
\text { strength } \\
(\mathrm{MPa})\end{array}$ & $\begin{array}{c}\text { Modulus } \\
\text { of } \\
\text { elasticity } \\
(\mathrm{GPa})\end{array}$ & $\begin{array}{c}\text { Elongatio } \\
\text { n }\end{array}$ & $\begin{array}{c}\text { Reduction } \\
\text { of area } \\
(\%)\end{array}$ \\
\hline \multirow{2}{*}{$\mathrm{II}$} & $\begin{array}{c}\text { Screw } \\
\text { thread }\end{array}$ & 12 & 210 & 352.4 & 475.3 & 190 & 25 & 23.8 \\
\hline
\end{tabular}

Table 4. Main performance indicators of FRP sheet after adhesive dipping

\begin{tabular}{cccc}
\hline Types of materials & Thickness $(\mathrm{mm})$ & Modulus of elasticity (GPa) & $\begin{array}{c}\text { Ultimate tensile strength } \\
(\mathrm{MPa})\end{array}$ \\
\hline CFRP & 1.123 & 27.35 & 716.8 \\
GFRP & 1.345 & 40.93 & 589.4 \\
JFRP & 1.205 & 35.75 & 665.87 \\
NFRP & 1.225 & 37.85 & 695.4 \\
\hline
\end{tabular}

\subsection{Test device and loading}

This axial compression test used a controlled electrohydraulic servo compression shear tester with a specification of $10000 \mathrm{kN}$, and adopted a loaddisplacement combined loading scheme. The loading adopted a hierarchical loading system. Each stage was loaded with 0.1 times of the ultimate compressive bearing capacity. The loading rate was $2 \mathrm{KN} / \mathrm{S}$ until the specimen enters the yielding state. After the specimen yields, the loading of each stage was changed to 0.05 times the ultimate compressive bearing capacity, and the loading rate was $1 \mathrm{KN} / \mathrm{S}$. During the test, each stage of loading needed to be stable for about 5 minutes. When the test piece entered the damage state, slow and continuous loading was adopted until the test piece was broken. Displacement meters were installed on the upper and middle parts of the test member to detect the vertical displacement and expansion displacement of the middle of the test member. The test device is shown in Figure 3.

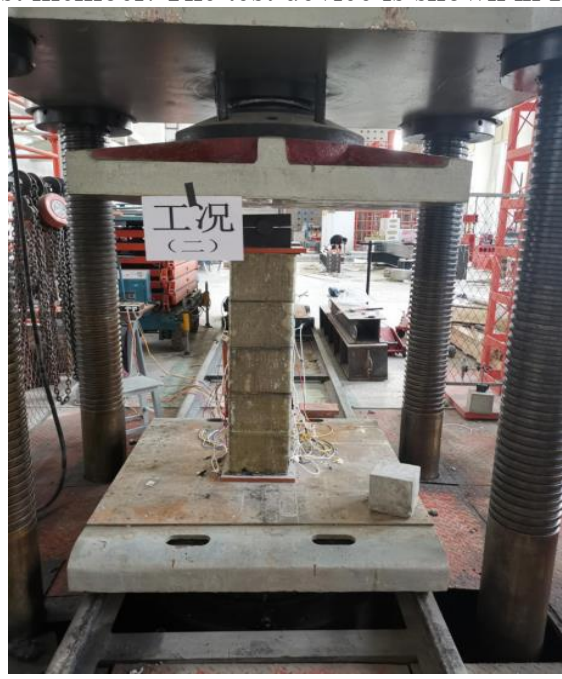

Fig. 3. Schematic diagram of the loading device

\subsection{Measurement arrangement}

These tests include: concrete strain test, steel bar strain test, axial compressive load test of column, vertical displacement and lateral displacement test. In this test, a total of 8 strain gauges were arranged on the steel bar in a concrete column, of which one strain gauge was arranged at the middle position of the four longitudinal reinforcements, and two strain gauges were respectively arranged at the two stirrups in the middle. The layout design of the stirrup strain gauge is shown in Figure 4. A strain gauge is longitudinally arranged at the middle position of the four sides on the outer surface of the concrete column, and a strain gauge was laterally pasted at the pasting position of the first layer of fiber cloth and the four side surfaces of the concrete pillar. A concrete strain gauge was affixed to each side between the fiber cloths, and the concrete strain gauge was arranged as shown in Figure 5.

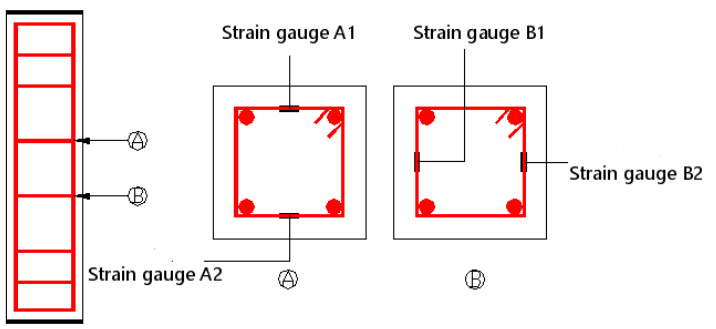

Fig. 4. Location of strain gauges at stirrups 


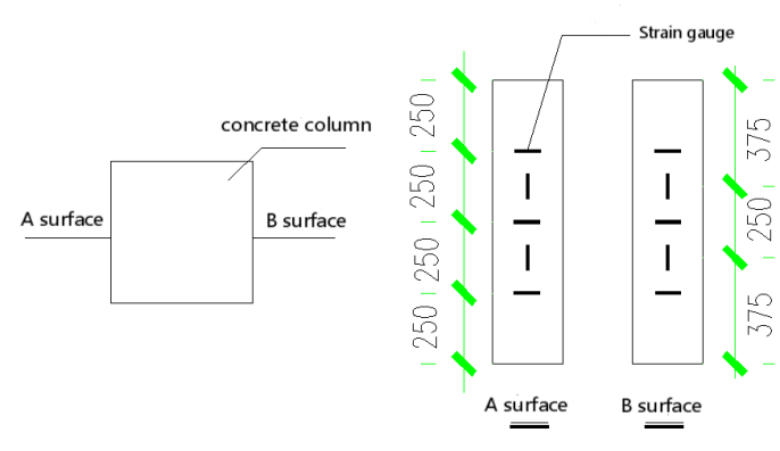

Fig. 5. Arrangement of concrete strain gauges

\section{Test results and analysis}

\subsection{Test phenomenon}

This test is an axial compression test of the five concrete square columns designed and manufactured above. The failure characteristics of the test columns are shown in Figure 6. The following are specific experimental phenomena:

In the comparison column $\mathrm{Z} 1$, when the load reached about $80 \%$ of the peak load, a micro-crack that began to extend vertically to the upper and lower column ends appeared in the upper and lower column corner positions of the test column. As the load continued to increase, multiple small cracks extending up and down the column ends appeared in the middle of the periphery of the column, and the width of the cracks gradually increased, and the cracks began to develop. When the test component reached the peak load, cracks developed rapidly, the concrete in the column bulged outward, and the axial and vertical strains of the concrete and the stirrup strain increased rapidly. In the middle of the periphery of the column, multiple oblique cracks extending $45^{\circ}$ upward and downward at the end of the column were finally formed. After the peak load was reached, the test column was damaged suddenly.

When the load of Z2 column reaches about $70 \%$ of the peak load, the sound of fiber cloth tearing was heard, and the sound of fiber cloth tearing was continuously emitted during the subsequent loading process. When the load reaches $90 \%$ of the peak load, a continuous fiber cloth tearing sound was emitted. After reaching the peak load, wrinkles, distortion and bulging of GFRP in the middle of the column can be observed. During this period, the bearing capacity of the test column basically stopped growing, but the deformation of the GFRP increased significantly. At the same time, the vertical strain and lateral direction of the test column concrete continued to increase. In the end, the GFRP fracture in the middle of the test column collapsed, the fracture location appeared at the corner, and developed rapidly up and down. The fracture was uneven, and the bearing capacity of the test column began to decline gently, and then the reinforced concrete test column was completely destroyed. After turning off GFRP, it can be observed that the cracks in the test column were larger than the crack width of $\mathrm{Z} 1$, but the number of cracks was smaller.
When the load of the Z3 column reaches $80 \%$ of the peak value, the center of the test column bulges outward. When the load reaches about $90 \%$ of the peak load, a sound of fiber cloth tearing was emitted, and the tearing sound continues until it is loaded to the peak load. GFRP in the middle part appears whitish due to tension. After reaching the peak load, the CFRP in the column suddenly broke at the corners, accompanied by a loud noise, and quickly developed upward and downward. The bearing capacity of the test column dropped rapidly, while the concrete part in the middle of the test column spattered outward, showing a more obvious crush. The CFRP fractures were relatively concentrated and appear on the same longitudinal plane, all of which were damaged near the corners, the fractures were relatively neat, the fiber cloth was completely separated from the concrete, and the concrete fragments were adhered to the fiber cloth. CFRP full-wrapped test columns still showed obvious brittle failure characteristics. After removing the fiber cloth, it was observed that the cracks in the test column were smaller than the crack width of $\mathrm{Z} 1$, and the number of cracks was slightly larger.

When the load of the Z4 column reached $80 \%$ of the peak load, it can be seen that the corner of the fiber cloth at the center of the test column began to whiten, accompanied by some sound of fiber cloth tearing and concrete cracking. When the test column reached the peak load, the sound of the fiber cloth breaking was heard, and the GFRP wound around the periphery of CFRP showed no obvious damage, and it could be determined that the internal CFRP had broken successively. In this case, the bearing capacity of the test column decreased to $90 \%$ of the peak load, then remained stable, and then the bearing capacity increased slightly. Then, the lateral strain and vertical strain of the concrete of the test column increased rapidly, and the concrete in the middle bulged significantly outward. In this case, the external GFRP began to tear, and a gap appeared, and then the GFRP suddenly broke at the corner, the bearing capacity of the test column dropped sharply, and the test column was completely destroyed. Compared with Z3 column, it had more obvious failure characteristics, showing more obvious ductile failure.

When the load of the Z5 column reached about $85 \%$ of the peak load, the fiber cloth began to turn white at the corner of the test column, and the sound of the fiber cloth breaking could be heard intermittently. At this stage, the load growth of the test column was slow, and the deformation growth was accelerated. When loaded to the peak load, a small amount of fiber cloth at the angular position of the middle of the test column broke, forming a gap, which was distributed longitudinally. In this case, the bearing capacity of the test column began to gradually decrease, and the lateral strain of the concrete in the middle increased. In the process of continuous loading, the center of the test column began to bulge outward, and the gap of the fiber cloth gradually developed. Subsequently, the fiber cloth in the center of the test column broke at the corner of the column, and at the same time, splits between the fiber bundles appeared. After the specimen is completely destroyed, the fiber cloth can effectively prevent the concrete fragments from jumping 
out. The fractures of the fiber cloth were uneven, showing the characteristics of graded destruction. When the fiber cloth was pulled away, the concrete in the middle of the test column was crushed and a gap appeared. During the entire loading process, the test column had obvious elastoplastic failure characteristics.

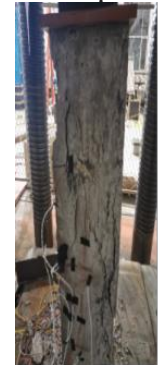

Z1

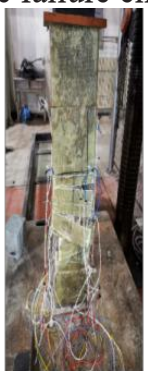

Z2

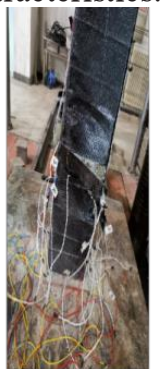

Z3

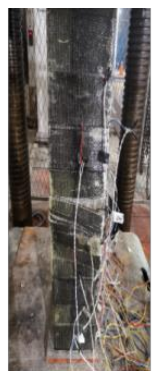

$\mathrm{Z4}$

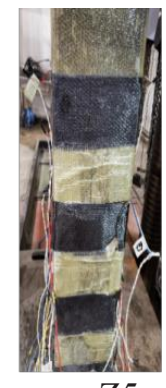

$\mathrm{Z5}$
Fig. 6. Failure characteristics of test column

\subsection{Analysis of test results}

\subsubsection{Analysis of reinforced concrete columns test data}

See Table 5 for the peak stress and peak strain of reinforced concrete square columns with different reinforcement methods. Among them, for the test members with brittle failure, the strain corresponding to the brittle failure point is taken as the ultimate strain, and for the test members with the fracture state of ductile failure, the corresponding strain when the bearing capacity drops by $15 \%$ is taken as the ultimate strain.

The above data shows: (1) The bearing capacity of the test column reinforced by the fiber cloth reinforced by the combination of two kinds of fibers is significantly improved, and the improvement rates are all above 30\%. The peak bearing capacity of the Z4 column and the Z5 column reached $87 \%$ and $93 \%$ of the peak bearing capacity of the Z3 column, respectively. (2) The fiber cloth composed of two kinds of fibers greatly increased the ultimate strain of the test column, which is slightly higher than the effect of GFRP reinforcement on the test column's ultimate strain, and far better than CFRP reinforcement on the test column's ultimate strain. The combined fiber cloth significantly improved the ductility of the test column. (3) The increase of longitudinal compressive strain of fiberglass cloth reinforced concrete is greater than that of transverse tensile strain, which shows that the fiber cloth has a good hoop effect. (4) Compared with Z5 column, Z4 column has better limit degeneration and lower axial load capacity.

Table 5. Peak stress and ultimate strain of test columns reinforced with different fiber cloths

\begin{tabular}{ccccccc}
\hline $\begin{array}{c}\text { Specimen } \\
\text { Number }\end{array}$ & $\begin{array}{c}\text { Peak stress } \\
(\mathrm{MPa})\end{array}$ & $\begin{array}{c}\text { Stress increase } \\
(\%)\end{array}$ & $\begin{array}{c}\text { Transverse } \\
\text { ultimate } \\
\text { tensile strain } \\
(\mu \varepsilon)\end{array}$ & $\begin{array}{c}\text { Strain } \\
\text { increase } \\
(\%)\end{array}$ & $\begin{array}{c}\text { Longitudinal } \\
\text { ultimate } \\
\text { compressive } \\
\text { strain }(\mu \varepsilon)\end{array}$ & $\begin{array}{c}\text { Strain } \\
\text { increase } \\
(\%)\end{array}$ \\
\hline Z1 & 24 & - & 822 & - & 1245 & - \\
Z2 & 28 & 17 & 1451 & 72.1 & 3084 & 1824 \\
Z3 & 36.8 & 54 & 1103 & 23.5 & 3679 & 46.5 \\
Z4 & 32 & 34 & 2410 & 105 & 3452 & 196 \\
Z5 & 34.4 & 43 & 2298 & 93 & 377 \\
\hline
\end{tabular}

\subsubsection{Stress-strain curve analysis}

For the five components of this test, the most typical stress-strain curve was selected to analyze the longitudinal strain, transverse strain, longitudinal reinforcement strain and stirrup strain of concrete.

The lines of the reinforced concrete test force-strain bending test column reinforced under different fiber cloth combinations are shown in Figure-. It can be observed that the stress-strain curve of fiber reinforced test columns can be divided into three stages.

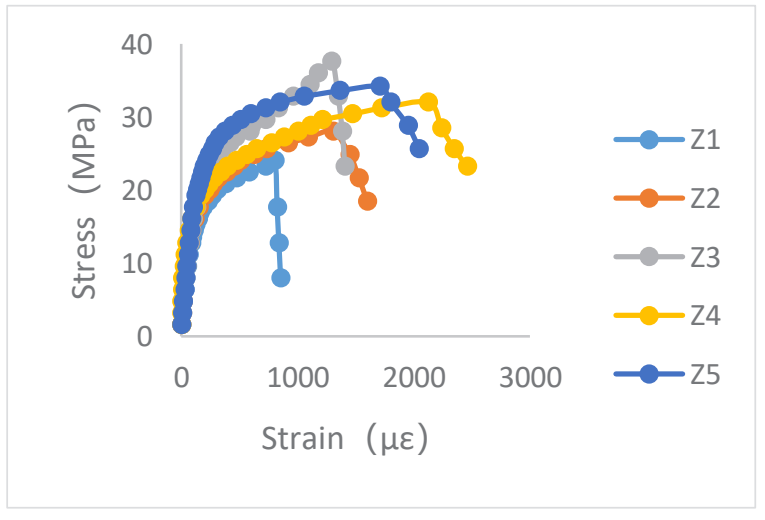

Fig. 7. Transverse stress-strain curve of concrete 


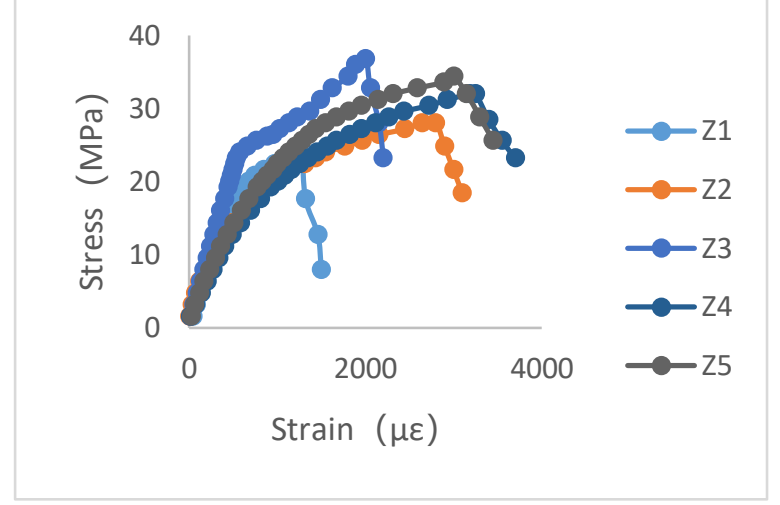

Fig. 8. Longitudinal stress-strain curve of concrete

1) Elastic stage. At this stage, the stress-strain curves of the concrete reinforced with fiber cloth and the concrete reinforced without fiber cloth remain basically the same, and the bearing capacity in this case is mainly borne by concrete.

2) Strengthening stage. At this stage, the concrete inside the test column began to crack and develop, and the concrete in the middle of the test column bulged laterally, so that the hoop strain of the fiber cloth increased significantly, which prompted the fiber cloth to begin to exert its hoop restraining effect, and in turn continues to increase the bearing capacity of concrete. At this stage, except for the comparison column Z1 (the slope of the stress-strain curve of $Z 1$ is the largest), the slope of the stress-strain curve of $Z 2$ is the smallest, the slope of the stress-strain curve of $Z 3$ is the largest, and the slope of stress- strain curve of Z4 and Z5 is between the above two, and the slope of the stress-strain curve of the Z4 column is smaller than that of the Z5 column. It shows that CFRP cloth has little improvement in the ductility of the test column, which is the closest to the curve shape of the comparative column; GFRP cloth has the greatest improvement in the ductility of the test column, which significantly strengthens the column's deformation ability; JFRP cloth and NFRP cloth can well improve the ductility of the column, and JFRP cloth can better improve the ductility of the test column.

3 ) Destruction stage. The axial load capacity of the test column began to decline, and the fiber cloth began to break until the test column was completely destroyed. At this stage, the stress-strain curve of the $\mathrm{Z} 1$ column is very steep, and the slope of the curve is the largest. The stressstrain curve of the Z3 and Z2 columns decreases more gently, the slope of the curve is the smallest. The slope of the stress-strain curve between Z4 and Z5 columns is between $\mathrm{Z} 2$ and $\mathrm{Z} 3$ columns, and is closer to the slope of the $\mathrm{Z2}$ column, and the stress-strain curves are slowly decreasing. It indicates that both $\mathrm{Z} 1$ and $\mathrm{Z} 3$ columns are brittle failures, and the damage is relatively sudden; $Z 2$, $\mathrm{Z} 4$, and $\mathrm{Z} 5$ columns are all ductile and have strong energy dissipation capacity.

Table 6 shows the ultimate strains of longitudinal bars and stirrups inside the test column under different fiber cloth combinations. Among them, for the test members with brittle failure, the strain corresponding to the brittle failure point is taken as the ultimate strain, and for the test members with the fracture state of ductile failure, the corresponding strain when the bearing capacity drops by $15 \%$ is taken as the ultimate strain.

Table 6. Ultimate strain of each test column

\begin{tabular}{ccccc}
\hline Specimen Number & $\begin{array}{c}\text { Ultimate strain of } \\
\text { longitudinal } \\
\text { reinforcement }(\mu \varepsilon)\end{array}$ & Stress increase (\%) & $\begin{array}{c}\text { Ultimate strain of } \\
\text { stirrups }(\mu \varepsilon)\end{array}$ & Stress increase $(\%)$ \\
\hline Z1 & -889 & - & 482 & - \\
Z2 & -5083 & 472 & 1278 & 165 \\
Z3 & -2380 & 168 & 649 & 34.6 \\
Z4 & -6727 & 656 & 720 & 49 \\
Z5 & -5754 & 547 & 693 & 43 \\
\hline
\end{tabular}


It can be seen that there is no obvious change in the stirrup strain law of the Z3 column, while the limit strain changes of the stirrups of the Z2 column, Z4 column, and Z5 column are significantly improved, and the lifting effect is similar; The improvement is relatively obvious. However, in comparison, the ultimate strain of CRPP cloth on the longitudinal reinforcement of reinforced concrete test columns is relatively low, and the ultimate strain of longitudinal reinforcement of test columns is significantly improved by GFRP, JFRP, and NFRP cloths, and the improvement rates are all above $450 \%$. Among them, GFRP cloth has the best enhancing effect, JFRP cloth is the second, and NFEP cloth has the lowest enhancing rate.

The load-strain curve of the longitudinal reinforcement of each test column is shown in Figure 9, and the load-strain curve of the stirrup is shown in Figure 10. Through analysis, it can be obtained: 1) After the steel bar yields, the bearing capacity of the comparison column $\mathrm{Z} 1$ is rapidly lost. However, the test column reinforced by fiber cloth can continue to bear after the steel bar yields, and the bearing capacity of the test column cannot continue to increase until the fiber cloth collapses. 2) The reinforcement of the comparison column Z1 entered the yield point earlier than the reinforcement of other test columns. The order of the reinforcement points of the fiber reinforced test columns into the yield point was: Z2 column steel bars, Z4 column steel bars, Z5 column steel bars, Z3 column steel bars. Moreover, the load of steel bar entering yield of Z4 column, Z5 column and Z3 column is close. 3) The stirrup strain value of the reinforced concrete test column reinforced with fiber cloth is small. Compared with $\mathrm{Z1}$ column, the stirrup strain value of the $Z 2$ column has increased by $165 \%$, and the stirrups of the $\mathrm{Z} 3$ column, the Z4 column, and the stirrup strain of Z3, $\mathrm{Z} 4$ and $\mathrm{Z} 5$ columns did not increase significantly. The above test data shows that after the fiber cloth is strengthened, the fiber cloth has a hoop restraining effect on the test column, which causes the internal steel bars to be restrained accordingly, thereby causing the steel bar to lag behind; The restraining effect of the JFRP cloth, NFRP cloth, and CFRP cloth on the test column are close, and the force is strong, which restrains the deformation of the stirrup well. Among them, the CFRP cloth has the strongest restraining effect, and the NFRP cloth is the second. The restraining effect of GFRP cloth on the test column is low.

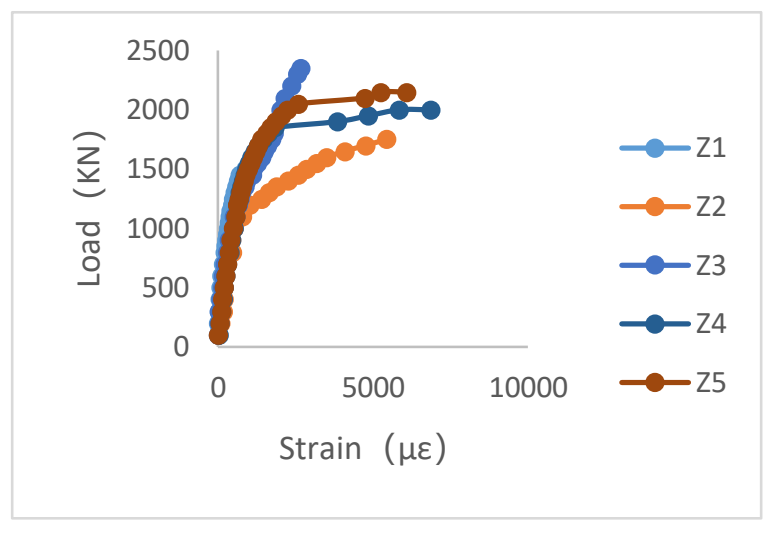

Fig.9. Stress-strain curve of longitudinal bars

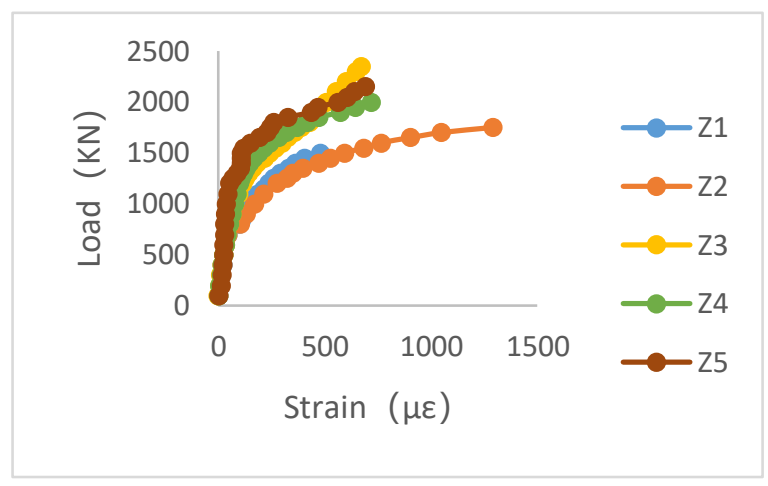

Fig.10. Stress-strain curve of stirrups

\subsubsection{Load-displacement curve analysis}

The load-axial displacement curve of the test column is shown in Figure 11, and the load-vertical displacement curve is shown in Figure 12.

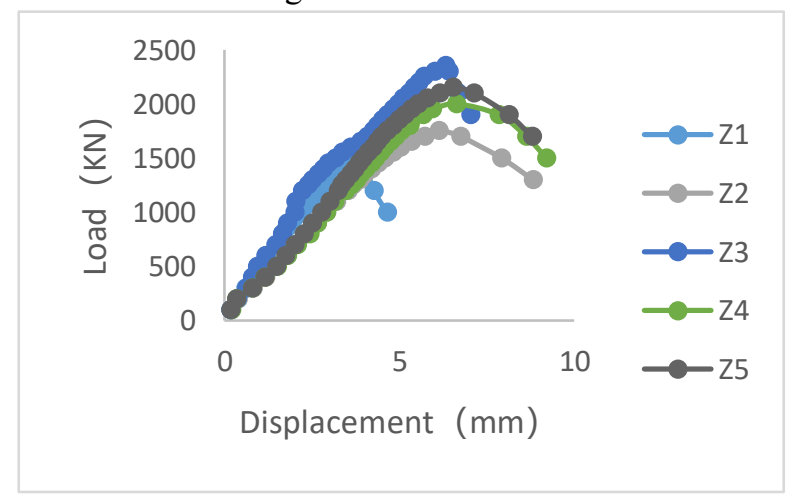

Fig. 11. Longitudinal load-displacement curves of concrete columns 


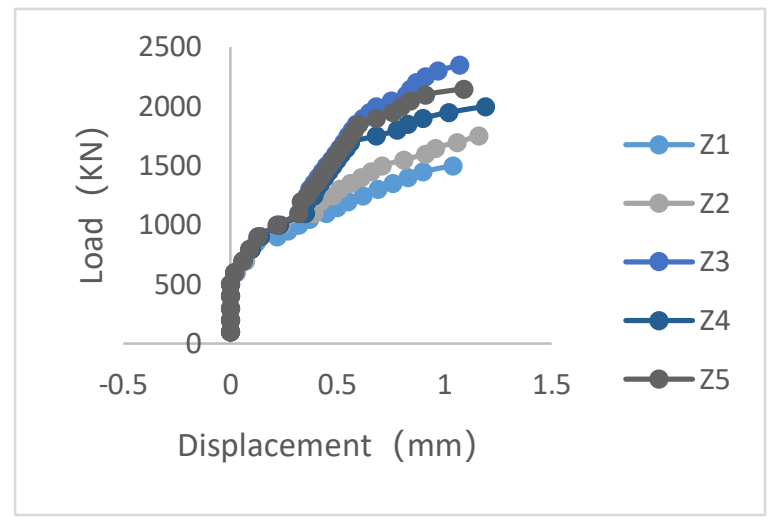

Fig. 12. Lateral load-displacement curves of concrete columns

In the early loading stage, the load-vertical displacement curves of the five fiber-reinforced test columns are approximately a straight line segment with a large slope, indicating that the test column in this case is in the elastic stage, and the load is mainly borne by the reinforced concrete, the fiber cloth does not play an obvious restraint. As the load increases, the reinforced concrete test column enters the elastoplastic stage. For Z1 and Z3 columns, the displacement load-vertical curve does not change significantly at this stage, that is, there is no good plastic deformation. The curves of $\mathrm{Z} 2, \mathrm{Z} 4$, and $\mathrm{Z} 5$ columns became gentler at this stage, that is, the load of the test column increased slowly while the displacement of the test column increased, indicating that these fiber cloths have improved the ductility of the column. During the failure stage of the test column, the load-vertical displacement curves of $\mathrm{Z} 1$ and $\mathrm{Z} 3$ columns dropped very abruptly, showing obvious brittle failure, while curves of Z2, Z4, and Z5 columns were relatively gentle at this stage, and the whole failure process has a good form of elastoplastic failure.

By observing the load- lateral displacement curve of each test column, it was found that for a long time from the beginning of loading, the hoop displacement of each test column did not increase significantly, and the Z1 and Z3 columns had lateral displacement only at the moment of failure, while the Z2, Z4, and Z5 columns began to show lateral displacement when they entered the plastic stage, and the displacement values were small. It shows that the fiber cloth has a good hoop restraining effect on the reinforced concrete test column, and the lateral deformation and displacement of the test column are strongly restricted.

\section{Conclusion}

(1) The combination of CFRP/GFRP between layers and the combination of CFRP/GFRP within the same layer can effectively improve the axial bearing capacity of reinforced concrete square columns, and the increase rates are all above $30 \%$, which is more than $85 \%$ of the lifting rate of the test column strengthened by single CFRP. And it can significantly improve the axial deformation capacity of reinforced concrete square columns, the increase rate is $170 \%$, which is far better than single CFRP reinforcement. It is of great significance to earthquakeresistant reinforcement.

(2) Under the same fiber material ratio, the axial load capacity of CFRP/GFRP combined layer in the same layer is greater than that of CFRP/GFRP combined between layers, but the enhancing rate of the axial deformation capacity of the column is slightly less than that of the interlayer composite CFRP/GFRP.

\section{References}

1. Chu Yunpeng, Hou Hongjie, Gan Lu, et al. Study on bend performance of damaged $\mathrm{RC}$ beam strengthened by hybrid FRP sheets [J]. Building Science, 2018,34(11):115-121+154.

2. Gu Qian, Dong Ge, Mekonnen Getahune Bitewlgn, et al. Test of seismic performance of earthquake damaged reinforced concrete columns strengthened with sprayed FRP [J]. Acta Materiae Compositae Sinica, 2016,33 (5): 1009-1019

3. Su Zhi. Axial compression properties of GFRPrecycled concrete-steel double-tube long columns. [D]. Guangdong University of Technology, 2016

4. Deng Zongcai, Li Jianhui. Study on restoring force model of RC corroded columns strengthened with hybrid FRP [J]. Engineering Mechanics, 2011,28 (8): 151-159

5. Chu Yunpeng, Hou Hongjie, Gan Lu, et al. Study on bend performance of damaged $\mathrm{RC}$ beam strengthened by hybrid FRP sheets [J]. Building Science, 2018,34(11):115-121+154.

6. Xiong Guangjing, Jiang Xiaoqing, Yang Jianzhong, et al. Experimental research of hybrid high strength glass fiber sheet/carbon fiber sheet strengthening 
concrete beams and columns [J]. Industrial

Construction, 2003 (09): 14-15 + 22

7. Christopher Quon,Lijuan Cheng,Yang Li,William $\mathrm{Yu}$. Confinement of concrete with hybrid FRP bistable structures[J]. Cement and Concrete Composites,2013,37.

8. Standard for test method of mechanical properties on ordinary concrete: GB / T 50081-2002 [S], 2003

9. General Administration of quality supervision, inspection and Quarantine of the people's Republic of China. Metallic materials - Tensile testing at ambient temperature: GB / T 228-2002 [S], 2002.

10. General Administration of quality supervision, inspection and Quarantine of the people's Republic of China and China National Standardization Administration. Fiber-reinforced plastics composites-Determination of tensile properties: GB / T 1447-2005 [S], 2005 